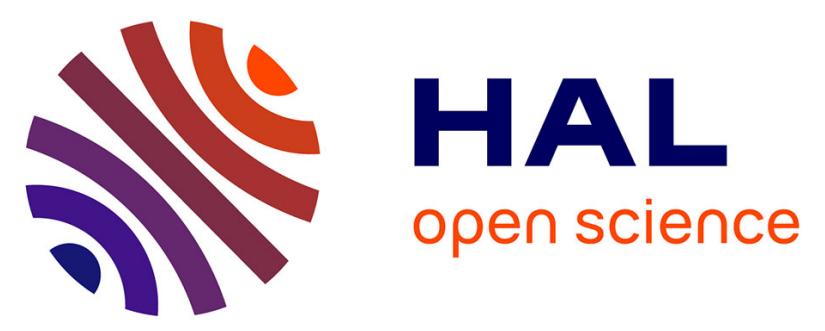

\title{
Relationship between structure, surface topography and tribo-mechanical behavior of Ti-N thin films elaborated at different $\mathrm{N} 2$ flow rates
}

\author{
Linda Aissani, Akram Alhussein, Abdelhak Ayad, Corinne Nouveau, Elia \\ Zgheib, Ahlam Belgroune, Mourad Zaabat, Régis Barille
}

\section{To cite this version:}

Linda Aissani, Akram Alhussein, Abdelhak Ayad, Corinne Nouveau, Elia Zgheib, et al.. Relationship between structure, surface topography and tribo-mechanical behavior of Ti-N thin films elaborated at different N2 flow rates. Thin Solid Films, 2021, 724, pp.138598. 10.1016/j.tsf.2021.138598 . hal03222691

\section{HAL Id: hal-03222691 \\ https://hal.science/hal-03222691}

Submitted on 10 May 2021

HAL is a multi-disciplinary open access archive for the deposit and dissemination of scientific research documents, whether they are published or not. The documents may come from teaching and research institutions in France or abroad, or from public or private research centers.
L'archive ouverte pluridisciplinaire HAL, est destinée au dépôt et à la diffusion de documents scientifiques de niveau recherche, publiés ou non, émanant des établissements d'enseignement et de recherche français ou étrangers, des laboratoires publics ou privés. 


\title{
Relationship between structure, surface topography and tribo-mechanical behavior of Ti-N thin films elaborated at different $\mathrm{N}_{2}$ flow rates
}

\author{
Linda AISSANI $^{\mathrm{a}, \mathrm{b}}$, Akram ALHUSSEIN ${ }^{\mathrm{c}, *}$, Abdelhak AYAD ${ }^{\mathrm{d}}$, Corinne NOUVEAU ${ }^{\mathrm{e}}$, \\ Elia ZGHEIB ${ }^{\mathrm{c}}$, Ahlam BELGROUNE ${ }^{\mathrm{a}, \mathrm{c}}$, Mourad ZAABAT ${ }^{\mathrm{a}}$, Régis BARILLE $^{\mathrm{f}}$ \\ ${ }^{a}$ Laboratory of Active Components and Materials, Larbi Ben M'Hidi University, Oum El Bouaghi, 04000, Algeria \\ ${ }^{\mathrm{b}}$ Physics Department, Abbes Laghrour - Khenchela University P.O 1252, 40004, Algeria \\ ${ }^{\mathrm{c}}$ LASMIS, Université de Technologie de Troyes, Pôle Technologique Sud Champagne, 26 Rue Lavoisier, 52800 Nogent, France \\ d Département de pharmacie, Faculté de Médecine, Université Salah Boubnider Constantine 3. Nouvelle ville Ali Mendjeli, Constantine, Algeria \\ ${ }^{\mathrm{e}}$ Arts et Metiers Institute of Technology, LABOMAP, HESAM Université, F-71250 Cluny, France \\ ${ }^{\mathrm{f}}$ Moltech Anjou, Université d'Angers/CNRS UMR 62002, Bd Lavoisier, 49045 Angers cedex, France
}

\section{Keywords:}

Titanium nitride

Magnetron sputtering

Microstructure

Hydrophobicity

Hardness

Adhesion

\begin{abstract}
A B S T R A C T
Titanium nitride films were deposited by reactive magnetron sputtering on Si (100) wafers, glass and Ti6Al4V substrates. The film deposition was carried out in a gas mixture of Ar and $\mathrm{N}_{2}$. The nitrogen content was varied between 0 and $30 \%$ of the total gas mixture. This variation led to the formation of different films with different microstructures. The microstructure of the Ti-N coatings presented nanocomposites with a low tendency to surface oxidation. From a pure $\mathrm{Ti}$ to tetragonal $\mathrm{Ti}_{2} \mathrm{~N}$ and cubic Ti-N microstructures, the films showed a (111) TiN plane growth that led to an increase in the lattice strain and a decrease in the grain size when increasing the nitrogen flow rate. The water-film contact angle measurements showed that the surface hydrophobicity increased with the increase of nitrogen content in the film. Mechanical properties were measured and a strong dependence between microstructure and hardness was found. The Ti-N deposited under $20 \%$ of $\mathrm{N}_{2}$ exhibited the highest hardness, the best adhesion and wear resistance, and the lowest friction coefficient with the presence of (111) fiber texture.
\end{abstract}

\section{Introduction}

The protective transition metal nitride coatings are used for cutting tools and wear resistant parts thanks to their high abrasion resistance, thermal stability and corrosion resistance at high temperature [1-3]. Among these coatings, titanium nitride has been extensively studied in the last few years because of its special properties. The TiN coatings have good electrical and thermal conductivity, high hardness [2], preferred (111)-oriented texture [2], high strength and rigidity, excellent thermal stability and wear resistance [4-5]. These appreciable properties make it an attractive candidate for different technical applications as well as for the development of aesthetic uses, due to its golden color [6]. The Ti-N coating is used in large applications mainly in modern industrial systems and for products having excellent tribological and mechanical performances along with high corrosion resistance [7]. Over the years, several deposition techniques have been developed to reduce defects in binary Ti-N coatings. The most common techniques used are physical vapor deposition (PVD) [8] and chemical vapor deposition [9]. Among the various PVD methods, the magnetron sputtering technique has a low deposition temperature, large deposition area, low impurity level, high deposition rate and superior bonding strength [10]. Metal or non-metal films can be deposited on substrates by selecting the appropriate sputtering process, different target materials and gas mixture [10-13].

The effect of nitrogen content in titanium nitride was widely studied. L.J. Meng et al. [14], by using X-ray diffraction (XRD), indicated that all films had a predominate (111) crystalline plane and that the grain size decreased at high nitrogen partial pressure. S. Schiller et al. [15] reported that the hardness of Ti-N varied between 20 and $30 \mathrm{GPa}$ as a function of N/Ti ratio. The maximum value of $30 \mathrm{GPa}$ was achieved for a $\mathrm{N} / \mathrm{Ti}$ ratio $=0.6$. The partial pressure of nitrogen, injected in the deposition chamber, has a significant effect on the tribological properties of the Ti-N film. According to Jianwei et al. [12], the Ti-N coating elaborated at $0.08 \mathrm{~Pa}$ had an internal stress of $0.09 \mathrm{GPa}( \pm 0.01)$, low wear and a friction coefficient of 0.37 .

\footnotetext{
* Corresponding author

E-mail address: akram.alhussein@utt.fr (A. ALHUSSEIN).
} 
Titanium nitride coating has a predominate (111) crystalline plane. It has great potential to be used for the protection of steels and tools [6]. In addition, nitrogen is a lubricated solid element with a low friction coefficient and wear rate that has also been used in severe industrial applications [15-21]. However, in the literature there has been insufficient investigation into the combination of mechanical, tribological and hydrophobic properties of sputtered TiN films (hardness, adhesion and wear resistance) and the texture (predominate plane and preferential orientation) [22]. They discussed either the influence of nitrogen content on the mechanical and tribological behavior without understanding the chemical bonding structure and the preferential orientation [10].

Therefore, the purpose of this study is to investigate the effect of nitrogen content on the performance of Ti-N films elaborated by the magnetron sputtering technique. We evaluated the combined effects of the partial pressure and flow rate of nitrogen injected in the deposition chamber on the structural, mechanical, hydrophobic and tribological properties of the sputtered titanium nitride films. This study focuses on the microstructural evaluation and allows the establishment of relationships between chemical composition, microstructure, texture, and functional properties of the Ti-N films.

\section{Experimental details}

\subsection{Deposition procedure}

Titanium nitride thin films with different compositions were deposited by magnetron sputtering at floating temperature. Si (100) wafers, glass and mirror polished Ti6Al4V substrates were used. The surface roughness $\left(\mathrm{R}_{\mathrm{a}} \approx 30 \mathrm{~nm}\right)$ of the Ti6Al4V substrates was measured with an optical profilometer. A $6 \mathrm{~mm}$ thick, $200 \mathrm{~mm}$ diameter circular titanium target ( $99.99 \%$ purity) was used. The substrates were ultrasonically cleaned in acetone and ethanol, dried in air and then fixed on the substrate-holder. The distance between the Ti target and the substrates was set to $100 \mathrm{~mm}$. The deposition chamber was evacuated down to $2 \times 10^{-4} \mathrm{~Pa}$, then a mixture of both $\mathrm{Ar}\left(99.99 \%\right.$ purity) and $\mathrm{N}_{2}(99.98$ $\%$ purity) gases was separately injected into the chamber. Prior to the film deposition, the Ti target was etched by Ar ions bombardment for 10 minutes. In order to increase the adhesion of Ti-N film on the substrate, a Ti interlayer $(\approx 60 \mathrm{~nm})$ was first deposited by applying $150 \mathrm{~W}$ to the Ti target in a pure Ar atmosphere of $50 \mathrm{sccm}$ for 10 minutes. Then, Ti-N films were deposited at a constant working pressure of $0.4 \mathrm{~Pa}$ by applying $250 \mathrm{~W}$ to the Ti target for $180 \mathrm{~min}$. The substrate-holder rotation was set at $10 \mathrm{rpm}$. The films were deposited under different $\mathrm{N}_{2}$ partial pressures and flow rates varied from $0 \mathrm{~Pa}\left(0 \% \mathrm{~N}_{2}\right)$ to $0.12 \mathrm{~Pa}$ ( $30 \% \mathrm{~N}_{2}$ of mixture atmosphere).

\subsection{Characterization techniques}

The crystalline structures and textures of Ti-N films were analyzed by $\mathrm{X}$-ray diffraction using a Bruker D8 advance diffractometer equipped with a $\mathrm{Cu}-\mathrm{K} \alpha$ radiation tube $(\lambda=0.15418 \mathrm{~nm})$, operated at $40 \mathrm{kV}$ and 40 $\mathrm{mA}$. The tube was used in the point focus mode and a $1 \mathrm{~mm}$ collimator directed the incident beam. A $\theta-2 \theta$ scan was carried out for $2 \theta$ diffraction angles ranging from $30^{\circ}$ to $80^{\circ}$ with a scan step of $0.02^{\circ}$.

The Scherrer's formula considers the effect of crystallite size on the XRD peak broadening. The Williamson-Hall method is an easy and simplified one, according to which total broadening of XRD peak is due to the size and micro-strain of the nanocrystals and can be written as:

$\beta_{\text {total }}=\beta_{\text {size }}+\beta_{\text {strain }}$

For a dense structure, we can calculate the average crystallite size by using the corrected physical broadening with the help of Scherrer's equation [23]:
$\mathrm{D}=\frac{0.9 \lambda}{\beta \cos \theta}$

Where 0.9 is a dimensionless shape factor, $\lambda$ the X-ray wavelength $\left(\lambda_{\mathrm{Cu}}=\right.$ $0.154 \mathrm{~nm}), \beta$ (in rad) the line broadening at half the maximum intensity (full width half maximum) and $\theta$ the Bragg's angle of TiN phase.

The lattice strain can be calculated using the following equation:

$\varepsilon=\frac{\Delta a}{a_{b u l k}}$

Where $\varepsilon$ is the lattice strain in the direction of the a axis, $\Delta \mathrm{a}=\left(\mathrm{a}_{\mathrm{film}}-\right.$ $\left.\mathrm{a}_{\text {bulk }}\right), \mathrm{a}_{\text {film }}$ and $\mathrm{a}_{\text {bulk }}$ of the cubic $\alpha \mathrm{Ti}+\mathrm{N}$ and TiN phases.

For the pole figure acquisition, the azimuth angle $(\varphi)$ was varied between 0 and $360^{\circ}$ and the tilt angle $(\chi)$ was varied between 0 and $70^{\circ}$; to avoid defocus problems. The $2 \theta$ theoretical values of the TiN face centered cubic phase are $37.01^{\circ}, 42.96^{\circ}$ and $62.21^{\circ}$, respectively, for $\{111\},\{200\}$ and $\{220\}$ crystalline plane families. The step measurement on the sampling angles was defined using the equal area projection method [17]. The pole figures are determined using Diffrac-Texture software and are represented in stereographic projection.

The cross-section images of the deposited films were analyzed using a Hitachi S3500 N Scanning Electron Microscope (SEM-FEG). The chemical compositions of the films were analyzed using energy dispersive X-ray spectroscopy (EDX, Oxford INCA xact, $15 \mathrm{kV}$ ). The $\mathrm{N}$ and Ti contents were measured in different areas for each film and the precision of the obtained N/Ti ratios was about $3 \%$.

The roughness and surface topography were determined by using Atomic Force Microscopy (AFM, APE research) with a silicon nitride super tip. The AFM was operated in contact mode and the scan zone was $3 \times 3 \mu \mathrm{m}^{2}$. The films' thicknesses were determined using an Altisurf 500 optical profilometer.

The hydrophobicity of the films' surfaces was evaluated by the contact angle measurements based on the static sessile drop method [16]. Water droplets $(3 \mathrm{ml})$ were dropped onto the films and the contact angles were measured. The droplet profile was acquired using a camera (SCA Software for OCA and PCA Drpo6) aligned with the sample and a backlighting source.

The film hardness and reduced modulus were measured by the nanoindentation technique using a Nano Indenter XP (MTS-XP) system in continuous stiffness measurement option, equipped with a diamond Berkovich indenter tip (three-side pyramid). The tip penetration depth was limited to not exceed $10 \%$ of the film thickness to avoid the influence of the substrate.

The residual stresses generated in the films during the deposition procedure were calculated using the curvature method (Stoney's formula (Eq. 4)) [3]. The substrate-curvature radii before and after film deposition were measured with an optical profilometer (VEECO, Wyko-NT 1100).

$\sigma=\frac{E s}{6\left(1-\nu_{\mathrm{s}}\right)} \frac{\mathrm{t}_{\mathrm{s}}^{2}}{\mathrm{t}_{\mathrm{f}}}\left(\frac{1}{\mathrm{R}}-\frac{1}{\mathrm{R}_{0}}\right)$

Where $\mathrm{E}_{\mathrm{S}}(181 \mathrm{GPa})$ and $\nu_{\mathrm{S}}(0.28)$ are the Young's modulus and Poisson's ratio of an iron substrate, respectively. $t_{s}$ and $t_{f}$ are the thicknesses of the substrate and the deposited film, respectively, while $R_{0}$ and $R$ are the curvature radius before and after deposition, respectively [3].

The tribological behavior (friction coefficient) of the films was evaluated by sliding wear tests using a tribometer (CSM Instruments) under a ball-on-disc configuration. The films were tested at room tem-

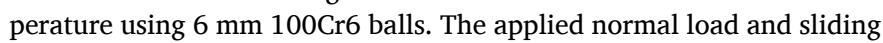
speed were $5 \mathrm{~N}$ and $10 \mathrm{~cm} / \mathrm{s}$, respectively. The adhesion strength of the as-deposited films was determined using a scratch tester (CSM instruments) equipped with a $200 \mu \mathrm{m}$ radius diamond tip. During the test, the applied load was raised monotonously up to a maximum value of 50 $\mathrm{N}$. The scratch tracks were observed using an optical microscope. 


\section{Results and discussion}

\subsection{Elemental chemical composition}

Ti-N thin films were deposited in a gaseous mixture of $\left(\mathrm{Ar}+\mathrm{N}_{2}\right)$. The chemical compositions, determined by EDX, of Ti-N films deposited under different nitrogen flow rates, are shown in Table 1. Ti-N film deposited under $5 \%$ of $\mathrm{N}_{2}$ presented a low $\mathrm{N} / \mathrm{Ti}$ ratio of 0.17 , where the low nitrogen content might lead to form a pure Ti phase as observed in Cr-N coatings [19]. Increasing the $\mathrm{N}_{2}$ flow rate from 5 to $30 \mathrm{sccm}$ (\%) obviously led to a significant increase in the nitrogen content from 14 to 54 at.\% and to a decrease of titanium from 83 to 43 at.\%. The reduction of titanium with the addition of nitrogen was previously reported for different coatings [18-19]. The obtained N/Ti values were consistent with the stoichiometric data for the TiN phase (0.98-1.04) [19]. All Ti-N thin films contained a low amount of oxygen in the range of 2-5 at.\%, which is due to the residual oxygen in the vacuum chamber and the affinity of Ti with oxygen (during deposition or post-deposition).

\subsection{Crystalline structure}

The effect of $\mathrm{N}$ content on the crystal structure was studied using XRD, and the results are shown in Fig. 1. The XRD pattern of Ti-N thin film deposited at low nitrogen flow rate of $5 \%$ presents very sharp diffraction peaks of $\alpha \mathrm{TiN}$ and $\mathrm{Ti}_{2} \mathrm{~N}$ at $40.8,43.1,44.7$ and $46.7^{\circ}$, which indicates that the film had a low strain $(\varepsilon=0.0252 \pm 0.0008)$ and a slight decrease in the lattice parameter $\left(\mathrm{a}_{\mathrm{TiN}}=0.4205 \mathrm{~nm}\right)$. For the Ti-N films with a nitrogen content in the range of 21-32 at.\% (films deposited at 10 and $15 \%$ of $\mathrm{N}_{2}$ ), the diffraction patterns present peaks at $36.85^{\circ}$, $42.19^{\circ}, 61.88^{\circ}$ and $74.01^{\circ}$ corresponding respectively to (111), (200), (220) and (311) planes of the fcc-TiN phase. The peaks at $40.84^{\circ}, 43.01^{\circ}$ and $78.80^{\circ}$ correspond respectively to the (111), (200) and (220) planes of a tetragonal $\mathrm{Ti}_{2} \mathrm{~N}$ phase. With the increase of nitrogen flow rate up to $20 \% \mathrm{~N}_{2}$, the deposited film led to a 48 at.\% of nitrogen. The film structure exhibits (111) plane growth tendency with a gradually decrease of the (200) diffraction peak. In fact, the TiN preferred orientation is related to the strain and the surface energy. According to G. Lu, et al. [21], with the increase of $\mathrm{N}$ content, target contamination increases and the deposition rate of the film decreases, resulting in an increase of the surface diffusion ability of the deposited nitrogen and titanium and the preferential plane of the film changes from (200) to (111) [19]. The films having high $\mathrm{N}$ content (deposited at $30 \% \mathrm{~N}_{2}$ ) showed small diffraction peaks. The results obtained are in agreement

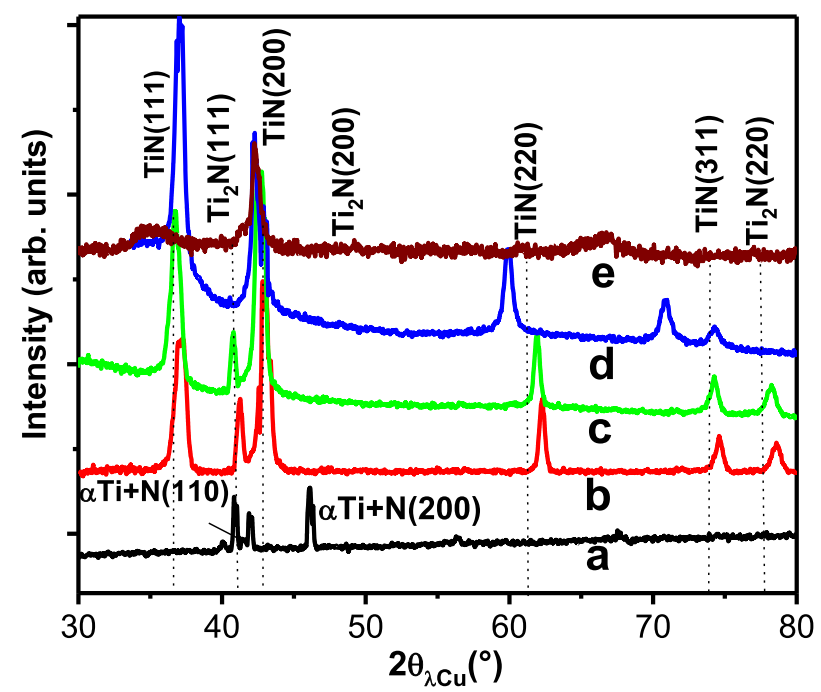

Fig. 1. XRD patterns of the Ti-N films deposited at: a) $5 \% \mathrm{~N}_{2}$, b) $10 \% \mathrm{~N}_{2}$, c) 15 $\% \mathrm{~N}_{2}$, d) $20 \% \mathrm{~N}_{2}$ and e) $30 \% \mathrm{~N}_{2}$. with those shown in the literature [21, 23-24].

It has been shown that the intensity and the lattice strain of the predominant (111) plane increased with increasing nitrogen content. The lattice constant slightly increases when the $\mathrm{N}$ atoms can preferentially occupy the interstitial positions of the metal nitride lattice [25-28]. However, the crystallite size decreased from ( $80 \pm 2.4)$ to $(64 \pm$ 1.9) $\mathrm{nm}$ when the amount of nitrogen increased from 14 to 48 at.\%. The grain size was found similar for films having small and high nitrogen content (Table 1). Using the corrected physical broadening, the average crystallite sizes of TiN phase calculated with the help of Scherrer's equation [29-35] were between $(64 \pm 1.9)$ and $(80 \pm 2.4) \mathrm{nm}$, which were higher than those reported by Arshi et al. (34-39 nm) [25].

\subsection{Morphology}

SEM and AFM are good complementary techniques used to determine the film morphology. Fig. 2 shows the morphology of the Ti-N films deposited under 10, 15 and $20 \%$ of $\mathrm{N}_{2}$ previously characterized by XRD (Fig. 1). It can be seen that both Ti underlayer and Ti-N film exhibited columnar structure. Approximately, the average columnar size of Ti-N films ranged between 20 and $50 \mathrm{~nm}$.

SEM cross section images and topography of the films deposited at different $\mathrm{N}_{2}$ show a significant difference in surface roughness and typical surface features. The main film characteristics, such as thickness and crystallite size are listed in Table 1 . At $10 \%$ of $\mathrm{N}_{2}$, the Ti-N film exhibited a columnar and packed structure consisting of well-separated grains with an apparently spherical form. A rough and domed surface was observed $(\mathrm{Ra}=12 \mathrm{~nm})$, corresponding to the transition zone between T and I zones of Andres' structural zone model [32]. This is due to the mutual interference of the intermediate $\mathrm{Ti}_{2} \mathrm{~N}$ and TiN phases [18]. From Fig. 2, we can see that increasing nitrogen content in film led to a reduction in roughness to $(\mathrm{Ra}=5 \mathrm{~nm})$. The reduction of both grain size and surface roughness are attributed to the dense structure and the smooth surface features. According to Zhou et al., the nitrogen plays an important role on the film smoothing due to the presence of more nuclei [33]. Furthermore, the reduction of the Ti-N film thickness containing high $\mathrm{N}$, deposited under high nitrogen flow rate, is because of the increase in gas molecule density, causing more collisions [32]. In addition, the target contamination by nitrogen can be another reason for this decrease [33]. According to Andres' structural zone model, the film with a fine-grained structure of textured and fibrous grains corresponds to zone 1 [32]. However, at high nitrogen flow rate $\left(30 \% \mathrm{~N}_{2}\right)$, we can observe that the average surface roughness increase (Ra) to $11 \mathrm{~nm}$ with a columnar structure corresponds to the transition zone between $\mathrm{T}$ and $\mathrm{I}$ zones of Andres' structural zone model. In the transition zone, diffusion is remarkable with the decrease in film density and the increase of defects during the film deposition. Diffusion through the grain boundaries is strongly limited leading to a competitive grain growth and resulting in a columnar structure with V-shaped and faceted grains that are not homogenous through the film thickness [32].

\subsection{Wetting behavior and hydrophobicity of films}

The interaction behavior between water and film surface was evaluated by the method of contact angle measurements. The contact angles of water droplets dropped onto the Ti-N films, deposited on glass substrates, were measured at ambient temperature. Fig. 3 shows the variation of film hydrophobicity and wettability as a function of the nitrogen flow rates. As we see, the initial contact angles between water-droplets and film surfaces deposited at different $\mathrm{N}_{2}$ flow rates of 5, 10, 15, 20 and $30 \%$ were $58.1^{\circ}, 86.4^{\circ}, 95.8^{\circ}, 109.6^{\circ}$ and $70.7^{\circ}$, respectively. After about one minute of exposure time, all contact angles were about zero. These results clearly showed that the films deposited between 10 and 20 $\% \mathrm{~N}_{2}$ had a high degree of wettability and its hydrophobicity increased with the increase of the nitrogen content in film. It has been reported that the gradual increase in contact angle indicated the reduction of 
Table 1

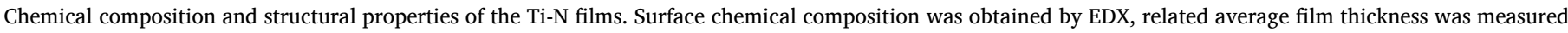
with an optical profilometer and lattice strain was calculated from XRD patterns.

\begin{tabular}{|c|c|c|c|c|c|c|c|c|}
\hline \multirow[t]{2}{*}{$\mathrm{N}_{2}$ partial pressure $\mathrm{Pa}$} & \multirow[t]{2}{*}{$\mathrm{N}_{2}$ gas flow $\%$} & \multicolumn{4}{|c|}{ Chemical composition, at.\% } & \multirow[t]{2}{*}{ Film thickness, $\mu \mathrm{m}$} & \multirow[t]{2}{*}{ Lattice strain, \% } & \multirow[t]{2}{*}{ Crystallite size, $\mathrm{nm}$} \\
\hline & & $\mathrm{N}$ & $\mathrm{Ti}$ & $\mathrm{O}$ & $\mathrm{N} / \mathrm{Ti}$ & & & \\
\hline 0 & 0 & 0 & 97 & 3 & 0 & $1.80 \pm 0.05$ & $0.0303 \pm 0.001$ & $87 \pm 2.6$ \\
\hline 0.02 & 5 & 14 & 83 & 3 & 0.17 & $1.65 \pm 0.05$ & $0.0252 \pm 0.001$ & $80 \pm 2.4$ \\
\hline 0.04 & 10 & 21 & 74 & 5 & 0.28 & $1.54 \pm 0.05$ & $0.8402 \pm 0.025$ & $79 \pm 2.4$ \\
\hline 0.06 & 15 & 32 & 65 & 3 & 0.49 & $1.45 \pm 0.04$ & $0.6369 \pm 0.026$ & $77 \pm 2.3$ \\
\hline 0.08 & 20 & 48 & 49 & 3 & 0.98 & $1.26 \pm 0.04$ & $0.7662 \pm 0.026$ & $64 \pm 1.9$ \\
\hline 0.10 & 25 & 50 & 48 & 2 & 1.04 & $1.10 \pm 0.03$ & $0.7920 \pm 0.028$ & $75 \pm 2.2$ \\
\hline 0.12 & 30 & 54 & 43 & 3 & 1.26 & $0.97 \pm 0.03$ & $0.5360 \pm 0.025$ & $79 \pm 2.4$ \\
\hline
\end{tabular}

a) $10 \% \mathrm{~N}_{2}$
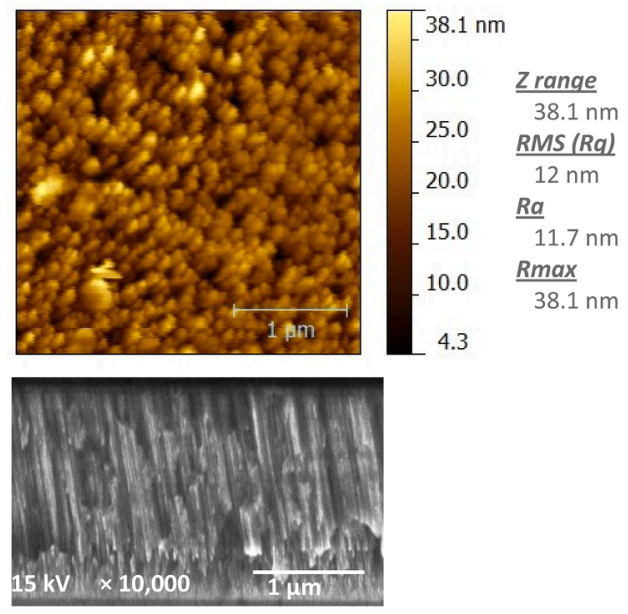

c) $20 \% \mathrm{~N}_{2}$
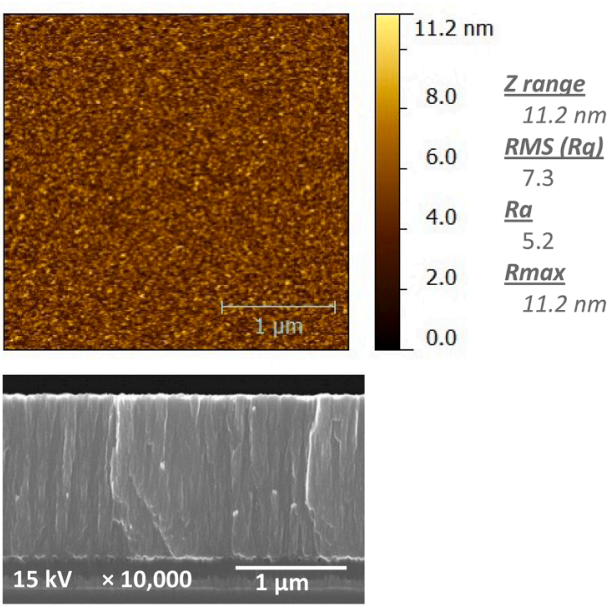

b) $15 \% \mathrm{~N}_{2}$
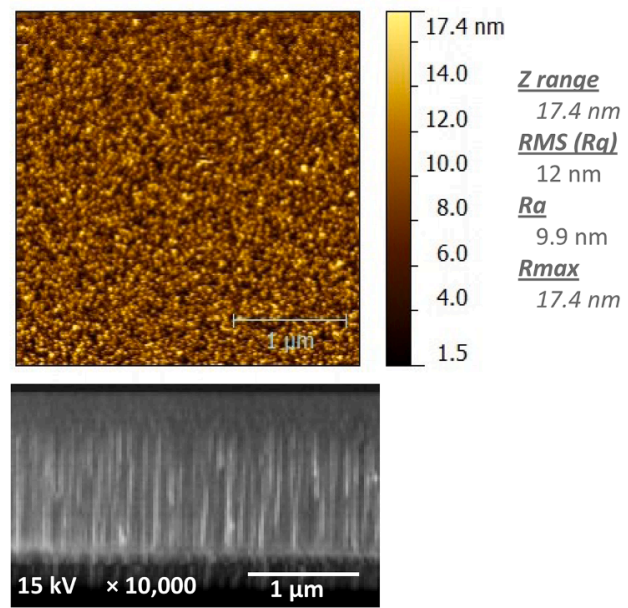

d) $30 \% \mathrm{~N}_{2}$
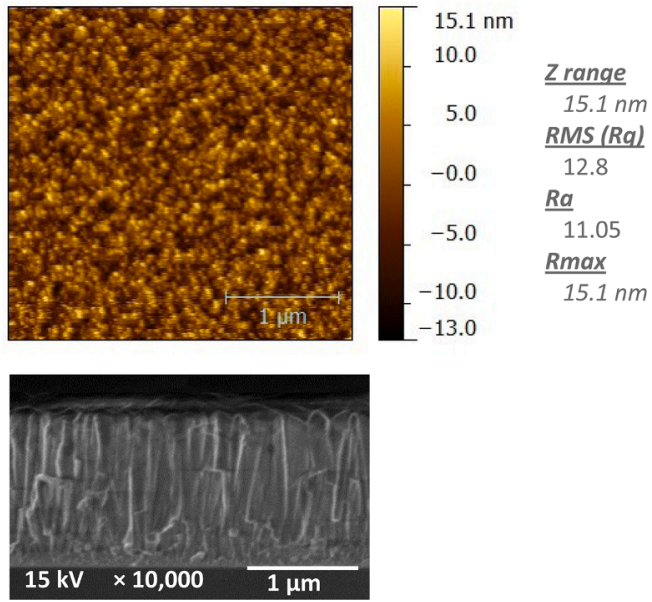

Fig. 2. 2D AFM and cross section SEM images of the Ti-N films deposited at: a) $10 \% \mathrm{~N}_{2}$, b) $15 \% \mathrm{~N}_{2}$, c) $20 \% \mathrm{~N}_{2}$ and d) $30 \% \mathrm{~N}_{2}$.

wettability [16]. Patel et al. obtained a similar result of about $99.5^{\circ}$ for the Zr-N films, which increased with increasing nitrogen flow rate [34]. It is noticed that when the surface roughness decreases, the contact angle increases. A gradual increase in contact angle was observed with an increase in surface homogeneity [16]. We can notice that increasing the nitrogen flow rate in plasma from 20 to $30 \%$ led to decrease the contact angle from $108^{\circ}$ to $70^{\circ}$, which is due to the low surface roughness.

\subsection{Mechanical properties}

\subsubsection{Residual stress}

The evolution of residual stresses generated in the Ti-N films, during sputtering under different nitrogen flow rates, is presented in Fig. 4. The pure titanium film had a tensile residual stress of $0.80 \mathrm{GPa}$. Increasing nitrogen flow rate from 5 to $30 \%$ and consequently its content in film, led to increase the compressive residual stress. This transition from tensile to compressive residual stress is correlated with the growth mechanism and the microstructure. It can be seen from Fig. 1 and Table 1 that changes in the predominant plan and the decrease of grain size play an important role on the evolution of residual stress. In fact, the grain size is reduced with the increase of nitrogen content and (111) TiN became the predominant plane, which is the close-packed plane having the highest surface energy $[29,35]$. So, tensile-to- compressive transition phenomenon is attributed to both the crystal densification effect and the effect of competitive grain growth with different orientation [29]. With increasing the nitrogen content, the ordering of atoms in the interstitial sites and annihilation of defects will lead to densification of 


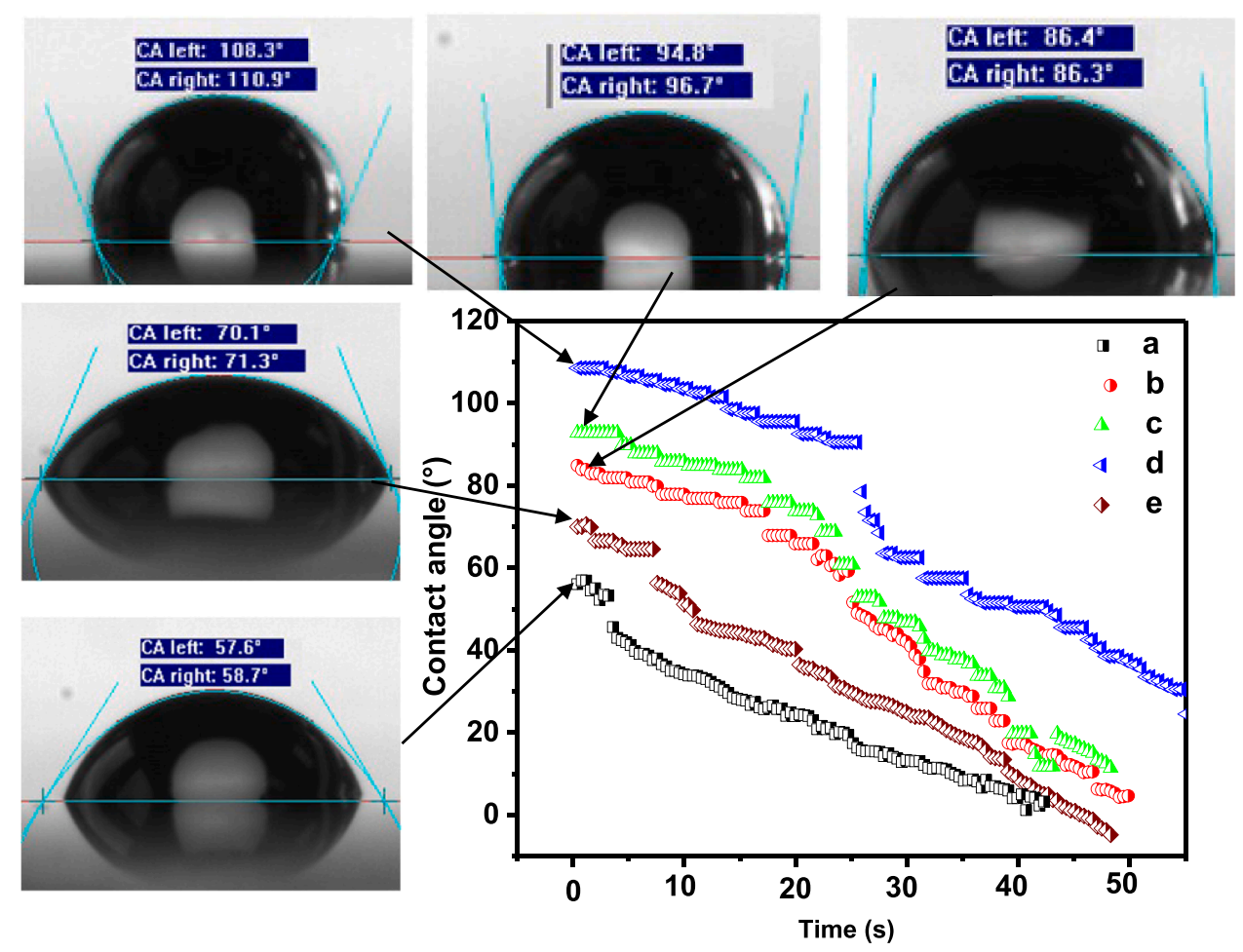

Fig. 3. Contact angles between water-droplets and Ti-N films deposited at: a) $5 \% \mathrm{~N}_{2}$, b) $10 \% \mathrm{~N}_{2}$, c) $15 \% \mathrm{~N}_{2}$, d) $20 \% \mathrm{~N}_{2}$ and e) $30 \% \mathrm{~N}_{2}$.

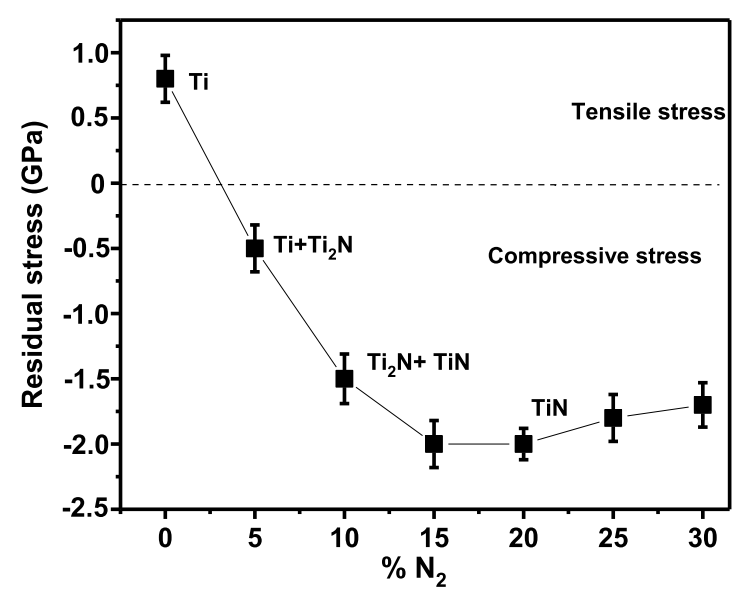

Fig. 4. Evolution of residual stress generated in the Ti-N films during the deposition at different $\mathrm{N}_{2}$ flow rates.

films. On the other hand, the insertion of extra atoms into the small grains is more difficult, thus tensile stress decreases and gradually transforms into compressive stress [30]. A compressive stress of -0.49 GPa was obtained in films sputtered at $5 \% \mathrm{~N}_{2}$ and increased continuously to reach its maximum value of $-2 \mathrm{GPa}$ in film deposited under 15 $20 \%$ of $\mathrm{N}_{2}$. A similar increase in stress with nitrogen content has been reported for the Ti-N [31] and Cr-N films [19]. Moreover, increasing nitrogen flow rate to more than $20 \%$ led to a slight reduction in the residual stress to about $-1.8 \mathrm{GPa}$. The decrease in the compressive stress could be due to the increase in the grain size, which leads to the enhancement of atom mobility and the relaxation of the structure density [36, 37].

\subsubsection{Nanoindentation measurements}

Fig. 5 presents the hardness $(\mathrm{H})$, reduced Young's modulus (E), (H/E) and $\left(\mathrm{H}^{3} / \mathrm{E}^{2}\right)$ of Ti-N films as a function of the $\mathrm{N}_{2}$ flow rates. The evolution of Young's modulus presents a very similar behavior as the results obtained for hardness. Thus, the hardness and Young's modulus of films, deposited at $\leq 5 \%$ of $\mathrm{N}_{2}$ are relatively low because of the low structure density. Increasing the nitrogen content, $\mathrm{H}$ and $\mathrm{E}$ of Ti-N films increased significantly. The highest hardness and Young's modulus of $(27.78 \pm 0.11) \mathrm{GPa}$ and $(304.8 \pm 10.6) \mathrm{GPa}$, respectively, were obtained for the film deposited at $20 \%$ of $\mathrm{N}_{2}$. This could mainly be attributed to the high compressive residual stress, the lower roughness and the fine grain size, which promote dislocation blocking and thus strengthening the coatings, according to the Hall-Petch relation [38]. The large amount of interstitial located nitrogen in the titanium matrix (about 48.5 at.\%) led to form new hard compounds and solid solutions in the structure and generated high strain (Table 1) due to the lattice defects [39]. The results showed clearly that the main hardening mechanism was related to the nitrogen concentration. In fact, titanium nitride coatings with high nitrogen content present a high fraction of TiN phase. The formation of hard ionic Ti-N and Ti-O-N bending energies as compared to the metallic Ti-Ti bending energy enhances the film mechanical properties.

However, when the nitrogen flow rate increased above $25 \%$, the decrease in the coating hardness was mostly caused by the reduction of film thickness (from 1.26 to $0.97 \mu \mathrm{m}$ ). The pollution of the Ti target during the deposition process could contribute to this softening behavior. In addition, the increase of the crystallite size (from 64 to 79 $\mathrm{nm})$ and the stress relaxation $(-1.8 \mathrm{GPa}$ ) seem to negatively influence the mechanical properties $[31,40]$.

The $\mathrm{H}$ and $\mathrm{E}$ values were used to determine $\mathrm{H} / \mathrm{E}$ and $\mathrm{H}^{3} / \mathrm{E}^{2}$ ratios (Fig. 5 b) $[38,40]$ that are useful to predict the wear behavior and toughness characteristics of coatings, respectively. The minimum values of $\mathrm{H} / \mathrm{E}=0.0213$ and $\mathrm{H}^{3} / \mathrm{E}^{2}=0.0028 \mathrm{GPa}$ were obtained for the coating deposited at low nitrogen flow rate of $5 \%$, indicating a low plasticity index and a poor resistance to plastic deformation, in agreement with other studies on Ti-N films [41, 42].

New generations of advanced, hard coatings for tribological and mechanical applications should combine the advantages of hard films with texture and preferred orientation. Pole figures are a good 

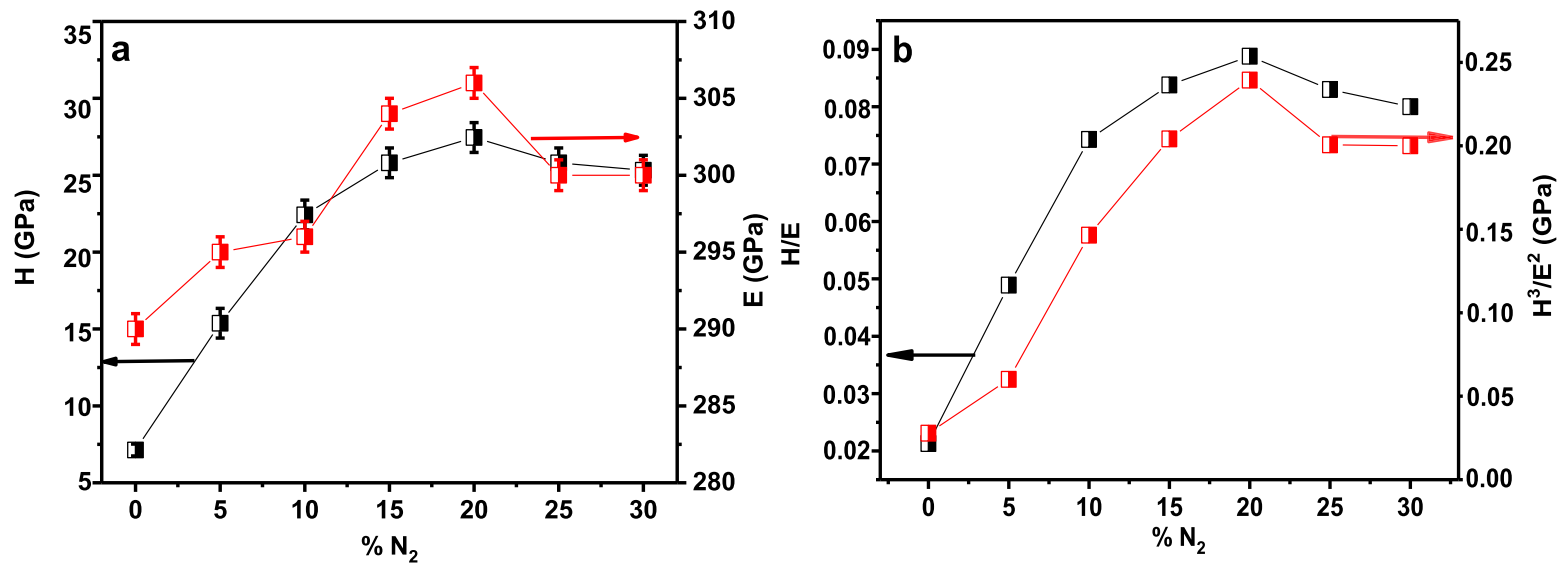

Fig. 5. a) Hardness $(H)$ and reduced Young's modulus (E), b) $(H / E)$ and $\left(H^{3} / \mathrm{E}^{2}\right)$ of the Ti-N films as a function of the $\mathrm{N}_{2}$ flow rate.

complementary method to determine the film texture. Figure 6 presents the experimental pole figures for the $\{111\},\{200\}$ and $\{220\}$ plane families of the TiN phase of films deposited with $10 \%$ and $20 \%$ of $\mathrm{N}_{2}$ previously characterized by XRD (Fig. 1) and gave a remarkable mechanical behavior. It should be noted that pole figures were obtained with adequate experimental $2 \theta$ angles, since there is a shift on the peak positions from theoretical values toward lower angles due to the influence of the nitrogen level on TiN structure. Ti-N film has variable chemical states and its chemical stability is over a broad composition range, as reported elsewhere [24, 25].

The central reinforcement of the $\{111\}$ pole figures shows the presence of a strong (111) texture (Fig. 6). Moreover, the diffuse intensity rings observed for $\{200\}$ and $\{220\}$ pole figures at $55^{\circ}, 35$ and $65^{\circ} \chi$ tilt angles respectively, are typical of a (111) fiber texture. Ti-N thin film deposited at $10 \%$ of $\mathrm{N}_{2}$ revealed very pronounced and sharp (111) fiber texture (small scatter width) with a heterogeneous intensity distribution leading to a dominant in-plane orientation (Fig. 6 (a)). With increasing the nitrogen flow rate from 10 to $20 \%$, the texture was weaker and the fiber was considered as perfect where the orientation density was uniformly distributed along the (111) fiber with a larger spread (about $7^{\circ}$ ) around the ideal fiber (Fig. 6 (b)). The decrease in $\{111\}$ texture intensity is due to the large dispersion of the (111) oriented crystallites around the sample's normal direction and their inplane rearrangements as shown by the large spread and the diffuse intensity ring, respectively (Fig. 6 (b)). It should also be noted that the film thickness was lower in the case of deposition at $20 \%$ of $\mathrm{N}_{2}$. It was 1.26 $\mu \mathrm{m}$ against $1.54 \mu \mathrm{m}$ for the film deposited at $10 \%$ of $\mathrm{N}_{2}$. Therefore, we predicted a lower diffracted volume (intensity) for this film, i.e. for the film deposited at $20 \%$ of $\mathrm{N}_{2}$. In these Ti-N films, the decrease in the deposition rate and relaxation of the film density was observed with increasing nitrogen flow rate. These results lead to an increase of the surface diffusion ability of the deposited nitrogen and enhance the titanium atoms' mobility. This result can favor plane growth with minimum energy deformation and easily takes random orientations in the
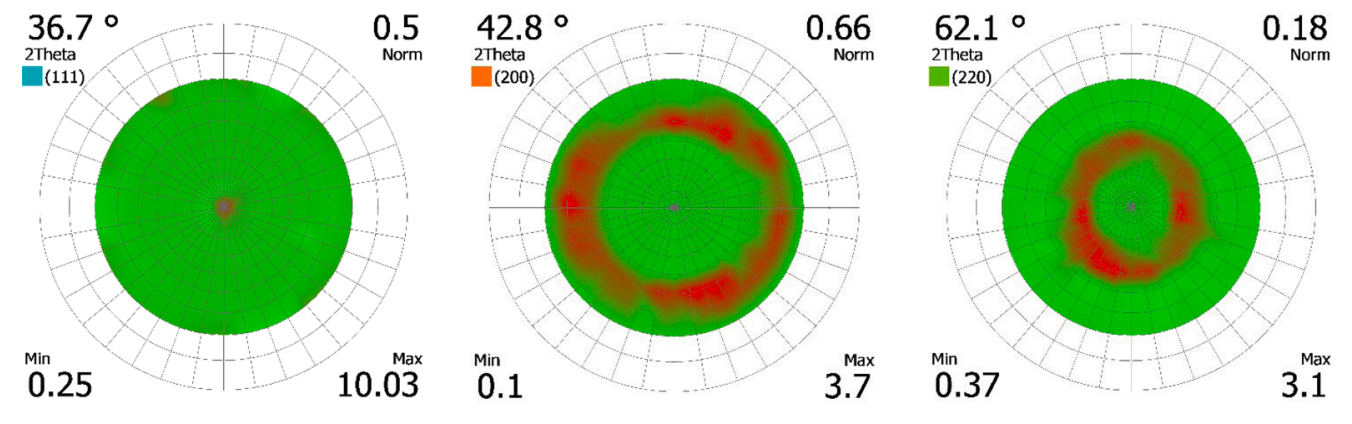

(a)
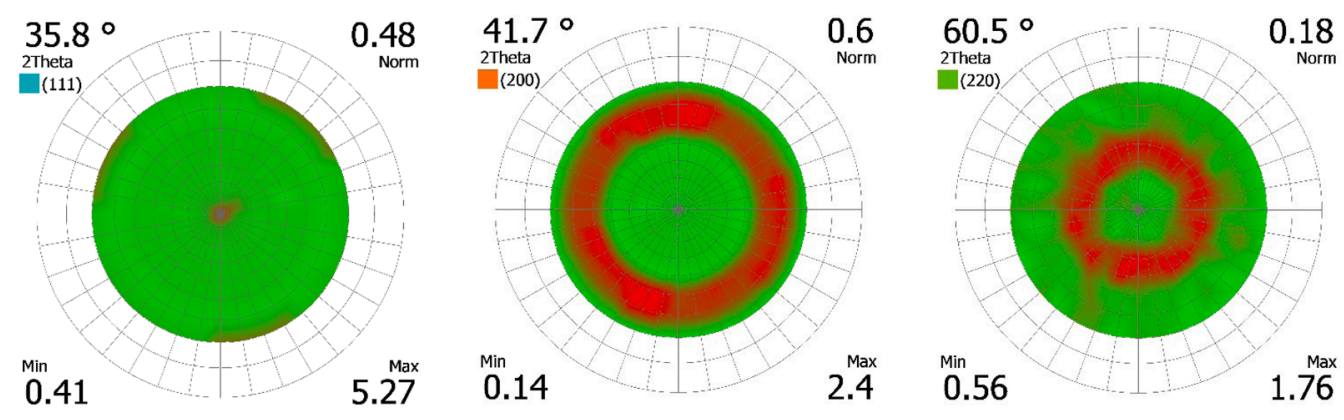

(b)

Fig. 6. $\{111\},\{200\}$ and $\{220\}$ experimental pole figures of the $\alpha$-TiN phase with a) $10 \% \mathrm{~N}_{2}$ and b) $20 \% \mathrm{~N}_{2}$. 
(111) fiber interior leading to a perfect (111) fiber texture as seen in Fig. 6 (b). The presence of a very high (111) texture is necessary for pseudo-epitaxial growth in Ti-N films, in order to use such films as under layers for growing metastable thin films in different multilayer systems $[27,28]$. It should be underlined that in all Ti-N thin films deposited by magnetron sputtering, a dominant (111) texture was found. However, texture was not perfect and strongly depended on the deposition parameters [23, 24].

According to the evolution of hardness and Young's modulus, the increase of nitrogen content led to an increase in the $\mathrm{H} / \mathrm{E}$ and $\mathrm{H}^{3} / \mathrm{E}^{2}$ values. The Ti-N film deposited under $20 \%$ of $\mathrm{N}_{2}$ flow rate presents the maximum values of $\mathrm{H} / \mathrm{E}$ and $\mathrm{H}^{3} / \mathrm{E}^{2} ; 0.0888$ and $0.2144 \mathrm{GPa}$, respectively. This is because of the high density columnar coalescence and the (111) predominance and the perfection of fiber texture of the densest packed plane. From Fig. 5, we can see that there is a direct relation between plastic strain and film hardness [43]. Then, films with higher $\left(\mathrm{H}^{3} / \mathrm{E}^{2}\right)$ and $(\mathrm{H} / \mathrm{E})$ ratios are more resistant to deformation. However, at higher nitrogen flow rate $20 \% \mathrm{~N}_{2}$, the lower degree of film texture led to a low crystallographic texture by the existence of (200) and (220) peaks in parallel with a predominate (111) peak and a low number of grain boundaries. The high quantity of nitrogen injected into the deposition chamber led to decrease the Ar ion bombardment energy and consequently the velocity of film growth (deposition rate) [43].

\subsection{Tribological properties}

\subsubsection{Friction coefficient}

Figure 7 shows the friction coefficients and critical loads of the coatings deposited at different nitrogen flow rates. Two critical loads were defined: the cohesive failure critical load $\left(\mathrm{Lc}_{1}\right)$, corresponding to the beginning of cracking in the coatings, and the adhesion failure critical load $\left(\mathrm{Lc}_{2}\right)$, corresponding to the chipping or the delamination of films.

The highest friction coefficient (COF) of $\sim(0.84 \pm 0.06)$ and the lowest critical loads $\left(\mathrm{Lc}_{1}=7 \pm 1 \mathrm{~N}, \mathrm{Lc}_{2}=11 \pm 1 \mathrm{~N}\right.$ ) were obtained for the films deposited at low nitrogen flow rate $\leq 5 \%$. This high COF is due to the low adhesion acting at the interface between the Ti-N coating and the substrate. When the nitrogen flow rate increased up to $20 \%$, the deposited film containing 48 at.\% of nitrogen presented the lowest friction coefficient of $\sim 0.36( \pm 0.06)$ and the highest critical loads ( $\mathrm{Lc}_{1}$ $=14 \mathrm{~N} \pm 1 \mathrm{~N}, \mathrm{Lc}_{2}=44 \pm 1 \mathrm{~N}$ ). This is due to the gradual grain refinement with increasing nitrogen flow rate producing a dense columnar structure containing small crystallite size $(64 \mathrm{~nm})$. These arguments are confirmed by the XRD data, which revealed mainly broad TiN peaks with high intensity. In addition, the high hardness of film is related to the predominant hard ionic Ti-N binding energy.

According to our previous work, this is attributed to the formation of

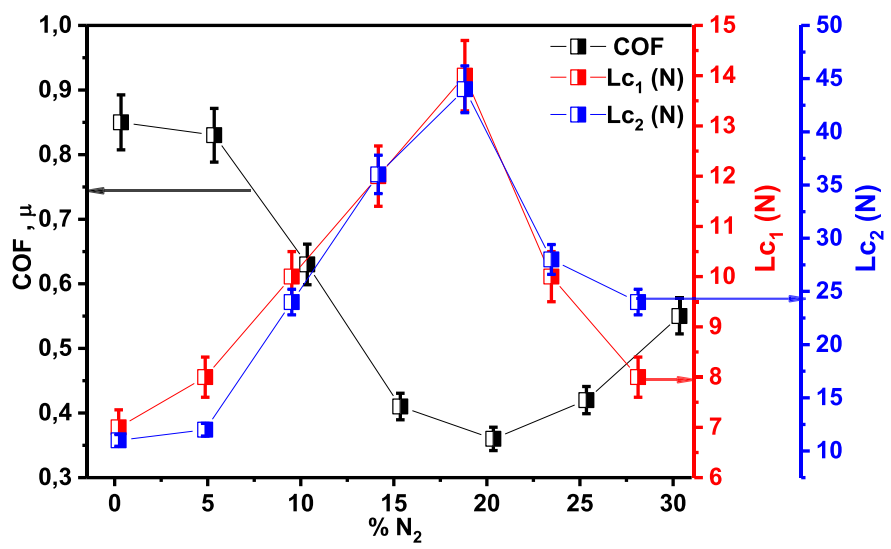

Fig. 7. Friction coefficients, $\mathrm{Lc}_{1}$ and $\mathrm{Lc}_{2}$ of the Ti-N films as a function of the nitrogen flow rate. oxides on the worn surfaces of the Ti-N coating that play a lubricant role between the two counterparts [18]. In addition, the presence of (111) TiN predominate plane in the film contributes to a low friction coefficient. Tanno et al. [44] have studied the effect of the grain preferred orientations on the friction coefficient of titanium nitride-based coatings. It has been found that the Ti-N films with (111) a preferential plan presented a low friction coefficient value of $\sim 0.2$. In another study on the tribological properties of the Ti-N coatings deposited on high-speed steel at low temperature $\left(150^{\circ} \mathrm{C}\right)$, Ali et al. [45] have reported that the friction coefficient was 0.55 . Comparing to these previous works, the friction coefficient values were in the range of $0.36-0.84$. In some cases, the friction coefficient is even lower than that of conventional PVD Ti-N coatings [44, 45].

\subsubsection{Adhesion}

The film-to-substrate adhesion strength was quantitatively measured using a scratch tester and the wear tracks on the coatings were observed with an optical microscope as shown in Fig. 8. In the scratch test, critical loads ( $\mathrm{Lc}_{1}$ and $\mathrm{Lc}_{2}$ ) could be used to calculate the adhesion strength. It is obvious in Fig. 7 that the critical loads followed an inverse trend as the friction coefficient. The film containing the lowest percentage of nitrogen (14 at.\%) wore out easily and delaminated from the substrate at the margins of the scratch track with a high amount of oxygen. This is the initial stage of the cohesive failure of the film which is related to its high
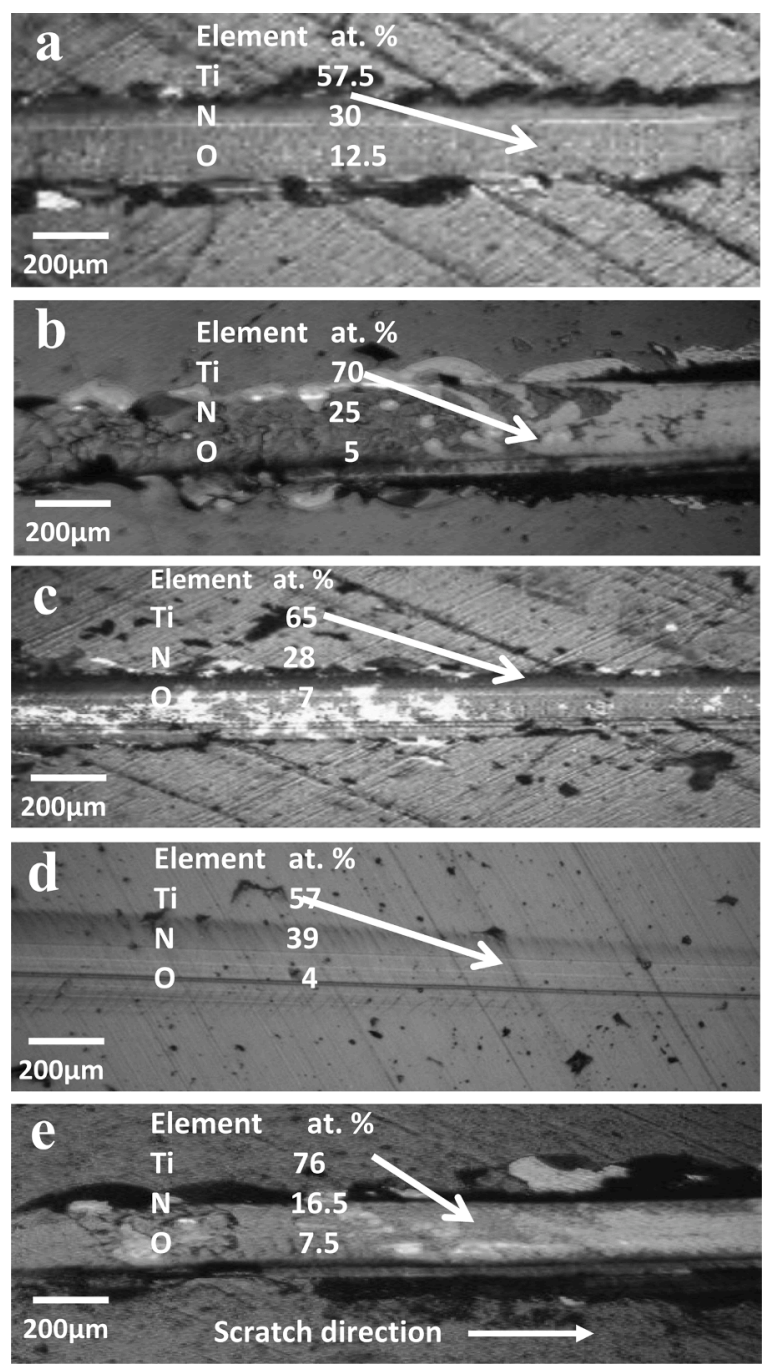

Fig. 8. Optical micrographs of scratch tracks performed on the Ti-N coatings deposited at: a) $5 \% \mathrm{~N}_{2}$, b) $10 \% \mathrm{~N}_{2}$, c) $15 \% \mathrm{~N}_{2}$, d) $20 \% \mathrm{~N}_{2}$ and e) $25 \% \mathrm{~N}_{2}$. EDX microanalyses of $\mathrm{Ti}, \mathrm{N}$ and $\mathrm{O}$ are also shown. 
friction coefficient (Fig. 8 a). The cohesive failure occurred at a low value of $7 \mathrm{~N}$; these kinds of cracks are often associated with a soft coating and a lowest value of $\mathrm{H} / \mathrm{E}$ ratio (0.074) that exhibited poor wear resistance [40].

For the Ti-N films deposited at 10 and $15 \%$ of $\mathrm{N}_{2}$ flow rate, their wear resistance is slightly improved and the wear passes the middle of the track onto the edge of the coating at higher applied loads $(27 \pm 1 \mathrm{~N}$ and $38 \pm 1 \mathrm{~N}$, respectively). The removal flakes appeared more complete in several areas of the substrate with a high amount of nitrogen (Fig. 8 b, c). One can notice that the wear resistance of the hard Ti-N coatings was higher than that of the other relatively soft coatings. This feature was observed for the Ti- $\mathrm{N}$ coating deposited at $20 \%$ of $\mathrm{N}_{2}$ flow rate where the wear track did not reveal any cracks or delamination and the highest critical loads were $\mathrm{Lc}_{1}=14 \pm 1 \mathrm{~N}$ and $\mathrm{Lc}_{2}=44 \pm 1 \mathrm{~N}$ (Fig. $8 \mathrm{~d}$ ). The best wear resistance of Ti-N coating with high nitrogen content is closely related not only to the N/Ti ratio, but also to the morphology and structure of Ti-N films [46]. A dense and smooth surface has less asperity or crevices as compared to porous coatings, which result in better interlocking and adhesion. On the other hand, the coating deposited at $20 \%$ of $\mathrm{N}_{2}$ was found to achieve the desired combination of hardness $(27.78 \pm 0.11) \mathrm{GPa}$, roughness $(5 \mathrm{~nm})$ and good wear resistance with higher $\mathrm{H} / \mathrm{E}(0.0888)$ that show a lower plasticity index and the best resistance, in agreement with other studies [42, 47]. The Ti-N film deposited at $20 \% \mathrm{~N}_{2}$ having a low thickness presented the highest hardness and critical loads and the lowest friction coefficient. Therefore, it can be predicted that a film with a low thickness has a higher adhesion to substrate and its resistance to failure will be better. However, for films deposited at a higher nitrogen flow rate (25\%), there was more debris along the edges of the track in the initial failure $\left(\mathrm{Lc}_{1}=(11 \pm 1) \mathrm{N}\right)$, while a complete failure of the Ti-N coatings occurred at a higher critical load $(32 \pm 1) \mathrm{N}$ due to the weak substrate-film cohesion (Fig. 8 e). These noticed failures might originate from the small film thickness and the differences in mechanical properties between the deposited film and substrate [48]. Regarding figures 5 and 7, we can see that the curve tendencies showing critical loads and hardness are similar.

The adhesion quality of a film depends on its chemical composition, defects and intrinsic properties. By varying the nitrogen flow rate, phase composition, microstructure and defects (dislocations, impurities and grain boundaries) become determinant parameters [25]. The enhancement of the film adhesion and its hardness with increasing nitrogen flow is also attributed to the grain refinement and the film stoichiometry where the nitrogen atoms occupy the interstitial positions in the $\mathrm{Ti}$ structure (table 1 and Fig. 1). The higher hardness related to the smaller grains increases the resistance to plastic deformation that results in an improvement in Ti-N film adhesion. The failure of the film could be mainly caused by the high compressive stress. The reduction of film adhesion and its hardness with increasing nitrogen flow (30\%) may be due to the over-stoichiometry, defects state and larger grain size.

\section{Conclusion}

Ti-N thin films were deposited under various nitrogen flow rates by using the reactive magnetron sputtering technique.

XRD data showed that the film phases changed from $\mathrm{Ti}$ to $\mathrm{Ti}_{2} \mathrm{~N}$ and TiN with increasing nitrogen content. The diffraction peaks shifted to lower angles with a (111) TiN preferential orientation indicating the presence of compressive residual stress. Increasing the nitrogen content in the Ti-N films led to increase the lattice strain in film crystals and decrease the film thickness and grain size.

The measurements of contact angles between water-droplets and $\mathrm{Ti}$ $\mathrm{N}$ film surfaces showed that all films had a high wettability. Increasing the nitrogen content in film led to increase its surface hydrophobicity. This can be related to the enhancement of surface softness as mentioned by the AFM and SEM images.

Nanoindentation measurements showed that hardness and Young's modulus of the coatings exhibited an increase from (7.1 GPa, 195.2 GPa) to $(27.78 \mathrm{GPa}, 304.8 \mathrm{GPa})$ when nitrogen flow rate was varied from 5 to $20 \%$, respectively. Consequently, both ratios increased H/E from 0.074 to $0.101 \mathrm{GPa}$ and $\mathrm{H}^{3} / \mathrm{E}^{2}$ from 0.095 to $0.244 \mathrm{GPa}$. Increasing the nitrogen content up to 48 at.\% in films led to enhance their hardness, elasticity modulus, resistance to plastic deformation and toughness.

The tribological tests showed that the lowest friction coefficient of $\sim$ 0.36 and the best adhesion were obtained for the Ti-N coating deposited at $20 \%$ of $\mathrm{N}_{2}$ flow rate (film containing 48 at.\% of nitrogen). This last configuration was confirmed as the best one and the addition of more nitrogen slightly decreased these properties.

In fact, the performances of hard film materials are highly influenced by their microstructure. In our study, increasing the nitrogen flow rate (increasing the $\mathrm{N}$ content in film) led to increase the film hardness because of the generation of a large number of point defects, where their density influences the texture and mechanical properties of the film. The high (111) textured film showed lower grain size resulting in an enhancement of its resistance. We found that Ti-N film deposited at $20 \%$ of $\mathrm{N}_{2}$ (film containing 48 at.\% of nitrogen) presented the best tribomechanical behavior, mainly due to its texture, compressive residual stress, geometrical strengthening, microstructure phases and their (111) preferred orientation and Ti-N binding energy formed in the film. According to these good results, some of which are confirmed by Recco et al. and Swygenhoven et al. [40, 42], we recommend the deposition process presented in this paper and the ideal configuration of film deposited at $20 \%$ of $\mathrm{N}_{2}$.

\section{CRediT authorship contribution statement}

Linda AISSANI: Conceptualization, Methodology, Formal analysis, Data curtion, Writing - original draft. Akram ALHUSSEIN: Conceptualization, Writing - original draft, Writing - review \& editing, Validation. Abdelhak AYAD: Methodology, Investigation. Corinne NOUVEAU: Resources, Writing - review \& editing, Validation. Elia ZGHEIB: Methodology, Software. Ahlam BELGROUNE: Methodology, Formal analysis. Mourad ZAABAT: Resources, Investigation. Régis BARILLE: Resources, Investigation.

\section{Declaration of Competing Interest}

The authors declare that they have no known competing financial interests or personal relationships that could have appeared to influence the work reported in this paper.

\section{References}

[1] C. Hu, Y. Tian, W. Zheng, A Review of corrosion-protective transition metal nitride coatings, Innovations in Corrosion and Materials Science 5 (2015) 2-9.

[2] L. Wang, D.O. Northwood, X. Nie, J. Housden, E. Spain, A. Leyland, A. Matthews, Corrosion properties and contact resistance of TiN, TiAlN and CrN coatings in simulated proton exchange membrane fuel cell environments, J. Power Sources 195 (12) (2010) 3814-3821.

[3] L. Aissani, A. Alhussein, C. Nouveau, L. Radjehi, I. Lakdhar, E. Zgheib, Evolution of microstructure, mechanical and tribological properties of vanadium carbonitride coatings sputtered at different nitrogen partial pressures, Surf. Coat. Technol. 374 (2019) 531-540.

[4] D. Edström, D.G. Sangiovanni, L. Hultman, I. Petrov, J.E. Greene, V. Chirita, Effects of incident $\mathrm{N}$ atom kinetic energy on TiN/TiN(001) film growth dynamics: A molecular dynamics investigation, J. Appl. Phys. 121- 025302 (2017) 1-10.

[5] J.M. Lackner, Industrially-scaled large-area and high-rate tribological coating by pulsed laser deposition, Surf. Coat. Technol. 200 (2005) 1439-1444.

[6] S.M. Borah, H. Bailung, J. Chuti, Decorative titanium nitride colored coatings on bell-metal by reactive cylindrical magnetron sputtering, Prog. Color Colorants Coat. 3 (2010) 74-80.

[7] P. Pedrosa, E. Alves, N.P. Barradas, N. Martin, P. Fiedler, J. Haueisen, F. Vaz, C. Fonseca, Electrochemical behaviour of nanocomposite Agx: TiN thin films for dry biopotential electrodes, Electrochim. Acta 125 (2014) 48-57.

[8] P. Leclair, G.P. Berera, J.S. Moodera, Titanium nitride thin films obtained by a modified physical vapor deposition process, Thin Solid Films 376 (2000) 9-15.

[9] L. Fieandta, T. Larsson, E. Lindahl, O. Bäcke, M. Boman, Chemical vapor deposition of TiN on transition metal substrates, Surf. Coat. Technol. 334 (2018) 373-383. 
[10] S. Zhang, F. Yan, Y. Yang, M. Yan, Y. Zhang, J. Guoa, H. Li, Effects of sputtering gas on microstructure and tribological properties of titanium nitride films, Applied Surface Science 488 (2019) 61-69.

[11] D. Hegemann, M. Amberg, A. Ritter, Recent developments in Ag metallized textiles using plasma sputtering, Mater. Technol. 4 (2009) 41-45.

[12] Q. Jianwei, Y. Yiming, Z. Mingming, C. Zhangbo, C. Kai, Effect of transition laye on the performance of hydroxyapatite/titanium nitride coating developed on Ti6Al-4V alloy by magnetron sputtering, Ceramics International 45 (4) (2019) 4863-4869.

[13] T. Zhou, D. Liu, Y. Zhang, T. Ouyang, J. Suo, Microstructure and hydrogen impermeability of titanium nitride thin films deposited by direct current reactive magnetron sputtering, J. Alloys Compd. 688 (2016) 44-50.

[14] L.J. Meng, M.P. Santos, Characterization of titanium nitride films prepared by d.c. reactive magnetron sputtering at different nitrogen pressures, Surf. Coat. Technol. 90 (1-2) (1997) 64-70.

[15] S. Schiller, U. Heisig, G. Beister, K. Steinfelder, J. Strümpfel, C. Korndörfer, W. Sieber, Deposition of hard wear-resistant coatings by reactive D.C. magnetron sputtering, Thin Solid Films 118 (1984) 255-270.

[16] J. Qi, Y. Yang, M. Zhou, Z. Chen, K. Chen, Effect of transition layer on the performance of hydroxyapatite/titanium nitride coating developed on Ti-6Al-4V alloy by magnetron sputtering, Ceramics International 45 (4) (2019) 4863-4869.

[17] M.F. Slim, A. Alhussein, E. Zgheib, M. François, Determination of single-crystal elasticity constants of the beta phase in a multiphase tungsten thin film using impulse excitation technique, X-ray diffraction and micro-mechanical modeling, Acta Materialia 175 (2019) 348-360.

[18] E. Lugscheider, K. Bobzin, Wettability of PVD compound materials by lubricants, Surf. Coat. Technol. 165 (2003) 51-57.

[19] X.S. Wan, S.S. Zhao, Y. Yang, J. Gong, C. Sun, Effects of nitrogen pressure and pulse bias voltage on the properties of $\mathrm{Cr}-\mathrm{N}$ coatings deposited by arc ion plating, Surf. Coat. Technol. 204 (2010) 1800-1810.

[20] L. Aissani, A. Alhussein, C. Nouveau, L. Ghelani, M. Zaabat, Influence of film thickness and Ar- $\mathrm{N}_{2}$ plasma gas on the structure and performance of sputtered vanadium nitride coatings, Surf. Coat. Technol. 378 (2019), 124948.

[21] G. Lu, L. Yu, H. Ju, B. Zuo, J. Xu, Influence of nitrogen content on the thermal diffusivity of TiN films prepared by magnetron sputtering, Surface Engineering 36 (2) (2020) $1-7$.

[22] A. Obrosov, R. Gulyaev, M. Ratzke, A.A. Volinsky, S. Bolz, M. Naveed, S. Weiß, XPS and AFM investigations of Ti-Al-N coatings fabricated using DC magnetron sputtering at various nitrogen flow rates and deposition temperatures, Metals 7 (52) (2017) 1-10.

[23] D. Nath, F. Singh, R. Das, X-ray diffraction analysis by Williamson-Hall, HalderWagner and size-strain plot methods of CdSe nanoparticles- A comparative study, Materials Chemistry and Physics 239-122021 (2020) 1-9.

[24] A. Kolitsch, X. Wang, D. Manova, W. Fukarek, W. Moeller, S. Oswald, Effects of titanium and aluminum incorporations on the structure of boron nitride thin films, Diamond and Related Materials 8 (2-5) (1999) 386-390.

[25] N. Arshi, J. Lu, B.H. Koo, C.G. Lee, F. Ahmed, Effect of nitrogen flow rate on the properties of TiN film deposited by beam evaporation technique, Applied Surface Science 258 (2012) 8498-8505.

[26] P. Prieto, R.E. Kirby, X-ray photoelectron spectroscopy study of the difference between reactively evaporated and direct sputter-deposited TiN films and their oxidation properties, J. Vac. Sci. Technol. A 13 (1995) 2819-2826.

[27] A. Singh, P. Kuppusam, S. Khan, Influence of nitrogen flow rate on microstructural and nanomechanical properties of $\mathrm{Zr}-\mathrm{N}$ thin films prepared by pulsed DC magnetron sputtering, Appl. Surf. Sci. 280 (4) (2013) 117-123.

[28] S.G. Zotova, U.R. Kaltofen, T. Sebald, DC reactive magnetron sputter deposition of (111) textured TiN films: influence of nitrogen flow and discharge power on the texture formation, Surf. Coat. Technol. 127 (2) (2000) 144-154.
[29] X. Yeting, G. Kewei, P. Xiaolu, Y. Huisheng, X. Xiaotao, L. Hong, A.A. Volinsky, Film thickness effect on texture and residual stress sign transition in sputtered TiN thin films, Ceramics International 43 (2017) 11992-11997.

[30] L. Zhang, H. Yang, X. Pang, K. Gao, A. Volinsky, Microstructure, residual stress, and fracture of sputtered TiN films, Surf. Coat. Technol. 224 (2013) 120-125.

[31] D.G. Constantin, D. Munteanu, The influence of nitrogen content on the mechanical properties of TiNx thin films prepared by reactive magnetron sputtering, Engineering Sciences 5 (54) (2012) 60-64.

[32] A. Andres, A structure zone diagram including plasma based deposition and ion etching, Thin Solid Films 518 (15) (2010) 4087-4090.

[33] W. Zhou, J. Liang, F. Zhang, J. Mu, H.A. Zhao, Comparative research on TiAlN coatings reactively sputtered from powder and from smelting TiAl targets at various nitrogen flow rates, Appl. Surf. Sci. 313 (2014) 10-18.

[34] N.P. Patel, K.V. Chauhan, J.M. Kapopara, N.N. Jariwala, S.K. Rawal, Characterization of sputtered zirconium nitride films deposited at various argon: nitrogen ratio, Mater. Sci. Eng. 149-012015 (2016) 1-9.

[35] S.K. Wu, H.C. Lin, P.L. Liu, An investigation of unbalanced-magnetron sputtered TiAlN films on SKH51 high-speed steel, Surf. Coat. Technol. 124 (2000) 97-103.

[36] L.C. Hernández, L. Ponce, A. Fundora, E. López, E. Pérez, Nanohardness and residual stress in TiN coatings, Materials 4 (12) (2011) 929-940.

[37] J.J. Olaya, S.E. Rodil, S. Muhl, L. Huerta, Influence of the energy parameter on the microstructure of chromium nitride coatings, Surf. Coat. Technol. 220 (2006) 5743-5750.

[38] Y. Xi, Y. Bai, K. Gao, X. Pang, H. Yang, L. Yan, A.A. Volinsky, Residual stress and microstructure effects on mechanical, tribological and electrical properties of TiN coatings on 304 stainless steel, Ceramics International 44 (2018) 15851-15858.

[39] P. Vlcak, J. Sepitka, J. Drahokoupil, T. Horazdovsky, Z. Tolde, Structural characterization and mechanical properties of a titanium nitride-based nanolayer prepared by nitrogen ion implantation on a titanium alloy, Journal of Nanomaterials 9214204 (2016) 1-7.

[40] H.V. Swygenhoven, M. Spacz, A. Care, Role of low and high angle grain boundaries in the deformation mechanism of nanophase Ni: A molecular dynamics simulation study, NanoStruct. Mater. 10 (5) (1998) 819-828.

[41] H. Cao, F. Qi, X. Ouyang, N. Zhao, Y. Zhou, B. Li, W. Luo, B. Liao, J. Luo, Effect of Ti transition layer thickness on the structure, mechanical and adhesion properties of Ti-DLC coatings on aluminum alloys, Materials 11 (1742) (2018) 1-13.

[42] A.A.C. Recco, C.C. Viafara, A. Sinatora, A.P. Tschiptschin, Energy dissipation in depth-sensing indentation as a characteristic of the nanoscratch behaviour of coatings, Wear 267 (5) (2009) 1146-1152.

[43] H. Scheerer, E.M. Slomski, C.Berger T.Trobmann, Characterization of CrN coatings concerning the potential to cover surface imperfections, Surf. Coat. Technol. 205 (2010) 47-50.

[44] Y. Tanno, A. Azushima, Effect of counter materials on coefficients of friction of TiN coatings with preferred grain orientations, Wear 266 (2009) 1178-1184.

[45] M. Ali, E. Hamzah, M.R. Toff, Friction coefficient and surface roughness of TiNcoated HSS deposited using cathodic arc evaporation PVD technique, Ind. Lubr. Tribol. 60 (2008) 121-130.

[46] L. Aissani, M. Fellah, L. Radjehi, C. Nouveau, A. Montagne, A. Alhussein, Effect of annealing treatment on the microstructure, mechanical and tribological properties of chromium carbonitride coatings, Surf. Coat. Technol. 359 (2019) 403-413.

[47] B.D. Beake, V.M. Vishnyakov, A.J. Harris, Relationship between mechanical properties of thin nitride-based films and their behavior in nano-scratch tests, Tribology International 44 (2011) 468-475.

[48] L. Aissani, M. Fellah, C. Nouveau, M.A. Samad, A. Montagne, A. Iost, Structural and mechanical properties of $\mathrm{Cr}-\mathrm{Zr}-\mathrm{N}$ coatings with different Zr content, Surf. Eng. 35 (2017) 1-9. 